\title{
Translation, cultural adaptation and validation of the Chinese Multimorbidity Treatment Burden Questionnaire(C-MTBQ): a study of older hospital patients
}

Liyuan Dou ${ }^{1+}$, Juan Huang ${ }^{2,3^{*}}$, Polly Duncan ${ }^{3}$ and Lixiang Guo

\begin{abstract}
Background: Due to an ageing population, multimorbidity is becoming more common. Treatment burden (the effort required of patients to look after their health and the impact this has on their wellbeing) is prevalent in patients with multimorbidity. The Multimorbidity Treatment Burden Questionnaire (MTBQ) is a patient-reported outcome measure of treatment burden that has been validated amongst patients with multimorbidity in the UK. The aim of this study was to translate and culturally adapt the MTBQ into Chinese and to assess its reliability and validity in elderly patients with multimorbidity in hospital.
\end{abstract}

Methods: The original English version of the MTBQ was translated into Chinese using Brislin's model of crossculture translation. The C-MTBQ was piloted on a sample of 30 elderly patients with multimorbidity prior to being completed by 156 Chinese elderly patients with multimorbidity recruited from a hospital in Zhengzhou, China. We examined the proportion of missing data, the distribution of responses and floor and ceiling effects for each question. Factor analysis, Cronbach's alpha, intraclass coefficient and Spearman's rank correlations assessed dimensional structure, internal consistency reliability, test-retest reliability and criterion validity, respectively.

Results: The average age of the respondents was 73.5 years (range 60-99 years). The median C-MTBQ global score was 20.8 (interquartile range 12.5-29.2). Significant floor effects were seen for all items. Factor analysis supported a three-factor structure. The C-MTBQ had high internal consistency (Cronbach's alpha coefficient, 0.76) and test-retest reliability (the intraclass correlation coefficient, 0.944 ), the correlations between every item and global scores scored $>0.4$. The scale content validity index(S-CVI) was 0.89 , and the item level content validity index(I-CVI)was $0.83 \sim 1.00$. The criterion validity was 0.875 .

Conclusion: The Chinese version of MTBQ showed satisfactory reliability and validity in elderly patients with multimorbidity, and could be used as a tool to measure treatment burden of elderly patients with multimorbidity in hospital.

Keywords: Elderly, Hospital, Treatment burden, Reliability, Validity, Multimorbidity

\footnotetext{
* Correspondence: huangjuan1980@163.com

†Liyuan Dou and Juan Huang contributed equally to this work.

${ }^{2}$ Party Secretary Office, People's Hospital of Zhengzhou, Zhengzhou, Henan

Province 450000, People's Republic of China

${ }^{3}$ Centre for Academic Primary Care, University of Bristol, Bristol BS6 6HL, UK

Full list of author information is available at the end of the article
}

(c) The Author(s). 2020 Open Access This article is licensed under a Creative Commons Attribution 4.0 International License, which permits use, sharing, adaptation, distribution and reproduction in any medium or format, as long as you give appropriate credit to the original author(s) and the source, provide a link to the Creative Commons licence, and indicate if changes were made. The images or other third party material in this article are included in the article's Creative Commons licence, unless indicated otherwise in a credit line to the material. If material is not included in the article's Creative Commons licence and your intended use is not permitted by statutory regulation or exceeds the permitted use, you will need to obtain permission directly from the copyright holder. To view a copy of this licence, visit http://creativecommons.org/licenses/by/4.0/ The Creative Commons Public Domain Dedication waiver (http://creativecommons.org/publicdomain/zero/1.0/) applies to the data made available in this article, unless otherwise stated in a credit line to the data. 


\section{Background}

Due to an ageing population, multimorbidity (two or more long-term conditions existing in one individual [1]) is increasing [2]. Studies have shown that the prevalence of multimorbidity in the elderly ( $\geq 65$ years) is greater than $60 \%$, and more than half of people with multimorbidity have three or more long term conditions [3]. Patients with multimorbidity experience higher disease burden than patients with single conditions and are at increased risk of high treatment burden- the effort required of patients to look after their health and the impact this has on their general wellbeing (e.g. attending multiple appointments with different health professionals, taking medicines at different times in the day) $[4,5]$. Studies have shown that high treatment burden is associated with reduced quality of life and adherence to treatment $[6,7]$, high hospitalization rates and high mortality [8].

There is a lack of research investigating treatment burden-for-patients with multimorbidity in China. Having a validated measure of treatment burden is essential to improving understanding of factors associated with high and low treatment burden, and to testing interventions that aim to reduce treatment burden. There is one existing generic measure of treatment burden that has been translated into Chinese, known as the Chinese Treatment Burden Questionnaire (C-TBQ). This measure was validated in a younger study population (median age 62 years). It is also a longer questionnaire to complete with 15 questions.

The multimorbidity treatment burden questionnaire (MTBQ) was developed and validated in the UK to assess treatment burden for patients with multimorbidity. Based on the treatment burden framework developed by Eton et al. [4] in 2012, the MTBQ is short, simple, and easy to use [9]. It was validated in over 1500 older patients (mean age 71 years) with multimorbidity ( $\geq 3$ long term conditions) and demonstrated good content validity, construct validity, reliability and responsiveness. The MTBQ has been translated into Danish and used in a population health survey, in which it showed good reliability and validity [10].

The purpose of this study was to translate and culturally adapt the MTBQ into Chinese and to test the psychometric properties of the questionnaire among Chinese-speaking elderly patients with multimorbidity in hospital.

\section{Method}

\section{Participants}

The data was collected from one hospital in Zhengzhou City, Henan province, China between August and October 2019. Patients were invited to take part if they met the following inclusion criteria: (1) complete hospital records and diagnosis at time of discharge; (2) two or more long term conditions; (3) age $\geq 60$ years. Patients were excluded if they had a serious physical or mental illness. The sample size of 156 was calculated using the Consensus-based Standards for the Selection of Health Measurement Instruments (COSMIN) [11]. This guideline advises 5-10 participants per item of the questionnaire. We slightly increased the sample size to account for incorrect filling of questionnaires.

\section{Questionnaires}

The Multimorbidity Treatment Burden Questionnaire (MTBQ) has 10 questions and three additional optional questions (questions which did not apply in a UK context but may apply to other populations). For the C-MTBQ, -these three additional questions were included. For each question, answers are ranked using a 5-point Likert scale, ranging from 0 (does not apply or not difficult), 1 (a little difficult), 2(quite difficult), 3(very difficult) and 4 (extremely difficult). The global MTBQ score is calculated as the mean score, multiplied by 25 , giving a score of 0 to 100 . Global treatment burden scores can be categorized as: no-treatment burden $(0)$, low treatment burden $(<10)$, medium treatment burden (10-22), high treatment burden $(\geq 22)$.

The Treatment Burden Questionnaire (TBQ) was originally developed by Tran [12] and measures the perceived treatment burden of patients with long term conditions. It has been translated into many countries $[12,13]$. It includes 15 questions and four dimensions: medication(1A 1D), seeing doctors and subsequent visit $(2 \mathrm{~A} \sim 2 \mathrm{E})$, medical related and lifestyle $(3 \mathrm{~A} \sim 3 \mathrm{E})$ and health problem(4A), A 10point Likert scale is used, ranging from 0 (no burden) to 10 (high burden). The global score of the TBQ is calculated as the sum of the answers to each item and ranges from 0 to 150 , with higher scores indicating a higher level of treatment burden.

\section{Translation process}

Researchers followed the Brislin model to translate the MTBQ into Chinese [14]. Step 1: The MTBQ was independently translated into Chinese by two researchers with Chinese linguistic backgrounds(T1, T2). T1 has a Master's degree and is medically trained and T2 has a postgraduate degree in English with no medical training. Step 2: A third researcher, who has a Master's degree in nursing and 6 years of IELTS training experience, reviewed and synthesized the translated versions created by $\mathrm{T} 1$ and $\mathrm{T} 2$, referring to the original English version. Step 3: two bilingual translators(One is a Master's degree student in English, the other is a Nursing PhD)back-translated the synthesized version into English to highlight conceptual errors in the translations. Step 4: All translators and team members compared the original MTBQ and the two backtranslation versions to form a comprehensive back- 
translation version to confirm accuracy [15]. The comprehensive back-translation was reviewed by the original MTBQ author(PD), and minor revisions were made until the comprehensive back-translation version and the original questionnaire had a semantic consistency rate of over $90 \%$.

\section{Cross-cultural adaptation}

Six experts conducted the cross-cultural adaptation: two general medical doctors; two hospital nurses who specialize in long-term conditions; a nurse who specializes in care of the elderly and the director of the care of the elderly hospital department.

They first evaluated the Chinese version of MTBQ in terms of accuracy, simplicity of the text, grammar, use of proper terms and syntax. The cultural relevance (language clarity, language habits, cultural background conformity and content relevance) and content validity were evaluated using a 4-point rating scale ranging from 1 (not relevant) to 4 (very relevant) to ensure the cultural applicability and content equivalence of the questionnaire [16]. The content validity index (CVI) (the proportion of questions rated by experts as either 3 or 4) was calculated.

\section{Piloting}

The final version of the MTBQ was piloted in 30 elderly patients who met the inclusion criteria. We found that they could understand the items easily and that they required an average of 5 minutes to finish the questionnaire.

\section{Questionnaire administration}

The questionnaires were administered face-to-face by three post-graduate students who were trained by the research team. Participants were identified by nursing staff working on the hospital wards. Data from the patient's hospital records was collected with written consent.

\section{Statistical analysis}

Data were analysed using SPSS version 21.0. Descriptive statistics were generated to describe the participants' characteristics. The distribution of responses for each question, proportion of missing data, proportion of 'does not apply' responses and floor and ceiling effects were examined. An exploratory factor analysis (EFA) was conducted to evaluate the dimensionality of the questionnaire [17], and the number of extracted factors was determined using the principal-component analysis (PCA) and varimax rotation. Factor loadings $(\lambda)>0.40$ or $<-0.40$ were considered acceptable [18].

To assess internal consistency reliability, we examined the inter-item correlation matrix and calculated
Cronbach's alpha (0.7-0.95 was deemed acceptable) [11, 19]. Test-retest reliability was assessed by comparing the total C-MTBQ scores in a subset of patients who completed the questionnaire on both day 0 and day 14 . The intraclass correlation coefficient (ICC) was calculated and interpreted as follows: excellent $(>0.8)$, good (0.61$0.80)$, moderate $(0.41-0.60)$, fair $(0.21-0.40)$ and poor $(\leq 0.20)$ [20]. To assess criterion validity, we examined the relationships between C-MTBQ and the Chinese version of the TBQ.

We examined the distribution of scores for each question. Ceiling and floor effects were considered to be present if more than $15 \%$ of respondents achieved the lowest (0) or highest (4) score, respectively.

\section{Ethical approval}

The study was approved by the ethics committee of People's Hospital of Zhengzhou. Written consent was taken for all the participants.

\section{Results}

Translation and cultural adaptation

"Health professionals" (questions 6, 7, and 8) was replaced by the traditional Chinese word for "medical staff" as the experts felt this was, the more commonly used expression. During interviews with participants, for the "appointments" in questions 6 and 8, the participants reports that there was no need to make an appointment to see a doctor in hospital mostly, so we removed the word "appointments". The item CVIs ranged from 0.83 $\sim 1.00$, while the scale CVI was 0.89 , indicating good content validity of the C-MTBQ.

\section{Description of sample}

One hundred and fifty-six participants completed the study. There characteristics are shown in Table 1. The average age was 73.5 years (60-99 years) with slightly more males (54.5\%). Less than a fifth had a college education. Two thirds of patients had three or more longterm conditions.

\section{The descriptive statistics of the C-MTBQ}

The proportion of missing data for each question was $0 \%$ (see Table 2). For the optional question about "Getting help from community health services (eg, physical therapy, health services provided by community nurses, etc.)", $64 \%$ of patients responded "does not apply". As this was greater than $40 \%$, this question was removed from the questionnaire. High floor effects (the proportion of participants who responded 'not difficult' or 'does not apply') were found for all questions. The range of skewness was between 0.453 and 2.093, and the range of kurtosis was between 0.040 and 3.721, indicating that the items of the C-MTBQ were non-normally 
Table 1 Sample characteristics $(n=156)$

\begin{tabular}{|c|c|c|}
\hline Characteristics & $\mathrm{N}$ & $\%$ \\
\hline \multicolumn{3}{|l|}{ Gender } \\
\hline Male & 85 & 54.5 \\
\hline Female & 71 & 45.5 \\
\hline \multicolumn{3}{|l|}{ Age(years) } \\
\hline $60 \sim 70$ & 63 & 40.4 \\
\hline $70 \sim 80$ & 46 & 29.5 \\
\hline $80 \sim 90$ & 40 & 25.6 \\
\hline$\geq 90$ & 7 & 4.5 \\
\hline \multicolumn{3}{|l|}{ Marital status } \\
\hline married & 132 & 84.6 \\
\hline Single/divorced/widowed & 24 & 15.4 \\
\hline \multicolumn{3}{|l|}{ Education Level } \\
\hline No formal/Primary education & 39 & 25.0 \\
\hline Secondary education & 91 & 58.3 \\
\hline Tertiary education & 26 & 16.7 \\
\hline \multicolumn{3}{|l|}{ Household income per month(Yuan) } \\
\hline$<1000$ & 30 & 19.2 \\
\hline $1000 \sim 3000$ & 41 & 26.3 \\
\hline $3000 \sim 5000$ & 53 & 34.0 \\
\hline$\geq 5000$ & 32 & 20.5 \\
\hline \multicolumn{3}{|l|}{ Living Status } \\
\hline Living alone & 22 & 14.1 \\
\hline Living with others & 134 & 85.9 \\
\hline \multicolumn{3}{|l|}{ Health insurance } \\
\hline Town medical insurance & 115 & 73.7 \\
\hline New Rural Cooperative & 27 & 17.3 \\
\hline Public medical care & 13 & 8.3 \\
\hline Others & 1 & 0.6 \\
\hline \multicolumn{3}{|l|}{ Long-term conditions } \\
\hline Cardiovascular Disease & 149 & 95.5 \\
\hline Stroke/Transient Ichaemic attack & 104 & 66.7 \\
\hline Diabetes & 81 & 51.9 \\
\hline Chronic kidney disease & 34 & 21.8 \\
\hline Chronic obstructive culnar disease or asthma & 20 & 12.8 \\
\hline Atrial fibrillation & 23 & 14.7 \\
\hline Depression & 7 & 4.5 \\
\hline Joint disease & 31 & 19.9 \\
\hline Heart failure & 14 & 9.0 \\
\hline \multicolumn{3}{|l|}{ Number of chronic diseases } \\
\hline 2 & 53 & 34.0 \\
\hline 3 & 72 & 46.2 \\
\hline 4 & 19 & 12.2 \\
\hline$\geq 5$ & 12 & 7.7 \\
\hline
\end{tabular}

distributed. The global C-MTBQ scores were skewed and varied from 2 to 60 . None of participants had a global C-MTBQ score of 0 , and no treatment burden $(0)$, low treatment burden $(<10)$, medium treatment burden(10-22) and high treatment burden $(\geq 22)$ accounted for $0,14.7,39.7$ and $45.5 \%$, respectively. The median C-MTBQ total score was 20.8 (interquartile range 12.5-29.2).

\section{Factor analysis}

The Kaiser-Meyer-Olkin (KMO) measure of sampling adequacy $(0.776)$ and the Bartlett test of sphericity $(p<$ 0.001 ) showed that factor analysis of the data was appropriate $[21,22]$. The scree plot is shown in Fig. 1. Three common factors were obtained, which explained the total variance of $54 \%$, loadings of all items ranged from 0.505 to 0.816 . The eigenvalue of the three factors were $-2.494,2.022$ and 1.960, respectively. The original English MTBQ had only one dimension. According to the content characteristics, factor $1(1,2,6,7)$ was named as the medication and treatment dimension (4 items); factor $2(3,4,8,9,13)$ was named as the medical related dimension (5 items), and factor 3(5、11,12) was named as the daily self-health management dimension. The three dimensions represented are shown in Table 3.

\section{Reliability}

The Cronbach's alpha and the corrected item-total correlations of all 12 questions are shown in Table 3. Itemtotal correlations ranged from 0.403 (item 9) to 0.701 (item 4), and all items met the recommended minimum of 0.20. Removing any item of the C-MTBQ didn't result in severely changing in the value of Cronbach's alpha. The internal consistency coefficient for the total score of the C-MTBQ were showed with a Cronbach's alpha of 0.755 . Thirty of the 156 participants were randomly selected to evaluate the test-retest reliability. The mean scores of the first and second measurements were 19.79 (interquartile range 19.79-29.17) and 21.00 (interquartile range 14.75-25.50), respectively. The test-retest reliability was satisfactory with an ICC of 0.944 .

\section{Criterion validity}

Correlations of C-MTBQ with TBQ and TBQ subscales scores are displayed in Table 4. The results suggested moderate to high correlations of C-MTBQ with TBQ score $(r=0.875)$ and TBQ subscales scores $(r: 0.495 \sim$ $0.740)$.

\section{Discussion}

In this study we have translated, culturally adapted and validated a 12-item questionnaire, named the Chinese Multimorbidity Treatment Burden Questionnaire (CMTBQ). We followed the standard forward-backward 
Table 2 Response to the C-MTBQ $(n=156)$

\begin{tabular}{|c|c|c|c|c|c|c|c|}
\hline Item, Description of item & $\mathrm{N}$ & $\begin{array}{l}\text { Not } \\
\text { difficult } \\
\text { n(n/N\%) }\end{array}$ & $\begin{array}{l}\text { A little } \\
\text { difficult } n(n / \\
\text { N\%) }\end{array}$ & $\begin{array}{l}\text { Quite } \\
\text { difficult } \\
\text { n(n/N\%) }\end{array}$ & $\begin{array}{l}\text { Very } \\
\text { difficult } \\
n(n / N \%)\end{array}$ & $\begin{array}{l}\text { Extremely } \\
\text { difficult } \\
\text { n(n/N\%) }\end{array}$ & $\begin{array}{l}\text { Dose not } \\
\text { applyn(n/N\%) }\end{array}$ \\
\hline 1. Taking lots of medications & 156 & $73(47)$ & $60(39)$ & 20(13) & $2(1)$ & $1(1)$ & $0(0)$ \\
\hline 2. Remembering how and when to take medication & 156 & $90(58)$ & $44(28)$ & 19(12) & $1(1)$ & $0(0)$ & $2(1)$ \\
\hline 3. paying for medications and treatment & 156 & $59(38)$ & $31(20)$ & 20(13) & $32(21)$ & 14(9) & $0(0)$ \\
\hline 4. take medicine regularly & 156 & $45(29)$ & $55(35)$ & $30(19)$ & $4(3)$ & $1(1)$ & $21(14)$ \\
\hline $\begin{array}{l}\text { 5.Monitoring your medical conditions (e.g. checking your blood } \\
\text { pressure or blood sugar, monitoring your symptoms etc.) }\end{array}$ & 156 & $34(22)$ & $46(30)$ & 29(19) & 20(13) & $2(1)$ & 25(16) \\
\hline 6. To see a doctor about a health issue & 156 & $59(38)$ & $62(40)$ & $27(17)$ & $4(3)$ & $0(0)$ & $4(3)$ \\
\hline 7. Go to see different doctors & 156 & $39(25)$ & $75(48)$ & 24(15) & $3(2)$ & $0(0)$ & 15(10) \\
\hline 8. getting time off work, arranging transport etc. to see doctors & 156 & $64(41)$ & $44(28)$ & $16(10)$ & $2(1)$ & $0(0)$ & $30(19)$ \\
\hline 9. Getting health care in the evenings and at weekends & 156 & $98(63)$ & $26(17)$ & $4(3)$ & $0(0)$ & $0(0)$ & 28(18) \\
\hline $\begin{array}{l}\text { 10. Getting help from community services (e.g. physiotherapy, district } \\
\text { nurses etc.) }\end{array}$ & 156 & 23(15) & 15(10) & $11(7)$ & $6(4)$ & $1(1)$ & $100(64)$ \\
\hline 11.Obtaining clear and up-to-date information about your condition & 156 & 29(19) & $65(42)$ & $32(21)$ & 26(17) & $4(3)$ & $0(0)$ \\
\hline 12.Making recommended lifestyle changes (e.g. diet and exercise etc.) & 156 & 30(19) & $65(42)$ & 45(29) & 10(6) & $0(0)$ & $6(4)$ \\
\hline 13.Must rely on support from family members and friends & 156 & $11(7)$ & $72(46)$ & 25(16) & $0(0)$ & $1(1)$ & $47(30)$ \\
\hline
\end{tabular}

translation process and examined the psychometric properties of the C-MTBQ in hospitalized Chinese elderly patients with multimorbidity. The C-MTBQ demonstrated good content validity, internal consistency reliability, test-retest reliability and criterion validity. A three-factor structure was found, which is different to the one factor structure of the original MTBQ.

The question 10 "Getting help from community health services (eg, physical therapy, health services provided by community nurses, etc.)" was deleted, because $64 \%$ of patients responded "does not apply". This may be due to differences between community health services in the UK and China, with primary care being less well developed in China and patients preferring to seek treatment from hospitals [23, 24].
The median C-MTBQ total score was 20.8, and the median C-TBQ score was 16 . It is difficult to draw comparisons since the global score for each questionnaire is calculated differently [25]. All the questions have high floor effects, which were similar to the C-TBQ. This may be in part due to the sample frame as all the participants were elderly, unemployed or retired and hence they had time to remember how and when to take medications and to monitor their medical conditions. Also they did not need to take time off work to see doctors. Further studies involving younger patient populations, particularly those with busy work patterns may reveal a different pattern of scores. A lack of a ceiling effect indicates that the C-MTBQ may be better for monitoring deterioration in treatment burden.

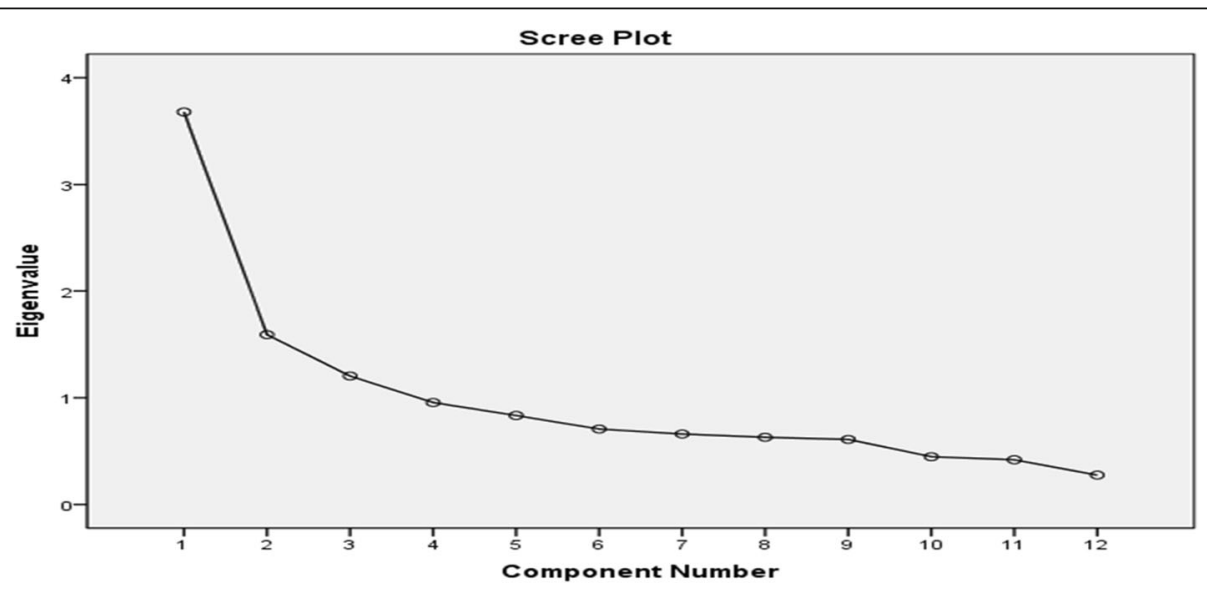

Fig. 1 Scree plot of C-MTBQ 
Table 3 Factor analysis, internal consistency of C-MTBQ

\begin{tabular}{|c|c|c|c|c|c|}
\hline Item & $\begin{array}{l}\text { medication and } \\
\text { treatment }\end{array}$ & $\begin{array}{l}\text { medical } \\
\text { related }\end{array}$ & $\begin{array}{l}\text { daily self-health } \\
\text { management }\end{array}$ & $\begin{array}{l}\text { Cronbach's Alpha if } \\
\text { Item Deleted }\end{array}$ & $\begin{array}{l}\text { Corrected item-total } \\
\text { correlation }\end{array}$ \\
\hline 1 & 0.816 & 0.081 & 0.063 & 0.736 & 0.527 \\
\hline 2. & 0.798 & -0.089 & 0.254 & 0.735 & 0.536 \\
\hline 6 & 0.641 & 0.296 & 0.341 & 0.715 & 0.695 \\
\hline 7. & 0.680 & 0.314 & -0.07 & 0.739 & 0.501 \\
\hline 3. & -0.226 & 0.708 & 0.119 & 0.778 & 0.455 \\
\hline 4. & 0.312 & 0.561 & 0.415 & 0.713 & 0.701 \\
\hline 8 & 0.202 & 0.619 & 0.068 & 0.738 & 0.514 \\
\hline 9 & 0.240 & 0.568 & -0.047 & 0.748 & 0.403 \\
\hline 13 & 0.086 & 0.505 & 0.453 & 0.731 & 0.573 \\
\hline 5 & 0.247 & -0.068 & 0.586 & 0.751 & 0.485 \\
\hline 11 & 0.033 & 0.171 & 0.716 & 0.736 & 0.564 \\
\hline 12 & 0.024 & 0.106 & 0.718 & 0.741 & 0.499 \\
\hline Eigenvalue & 2.494 & 2.022 & 1.960 & & \\
\hline $\begin{array}{l}\% \text { of Variance Explained (rotation } \\
\text { solution) }\end{array}$ & 20.780 & 16.850 & 16.337 & & \\
\hline $\begin{array}{l}\text { Cumulative } \% \text { of Variance Explained } \\
\text { (rotation solution) }\end{array}$ & 20.780 & 37.629 & 53.966 & & \\
\hline
\end{tabular}

A value of 0.40 or greater for the factor loadings was regarded as acceptable.

According to the results of factor analysis, all of the 12 questions of the C-MTBQ were grouped into three factors, and factor loadings reached the criteria of 0.40 . By comparison, the original MTBQ was unidimensional. This may have potential implications for instrument scoring. There are several explanations for this. Firstly, item 10 was deleted from the C-MTBQ. Secondly, the sample size for the C-MTBQ was small compared to the original English questionnaire which was validated in 1500 patients with multimorbidity $[9,26]$. Thirdly, the participants of the original questionnaire were $\geq 18$ years, participants of this research were aged $\geq 60$ years. Lastly, there are important cultural differences between the UK and China and this is likely to impact on perceived treatment burden [27]. In terms of criterion validity, the C-MTBQ correlated well with TBQ score $(r=0.875)$, which indicated that the C-MTBQ had a good criterion validity.

For the Internal consistency, the results showed a little lower internal consistency with a Cronbach's alpha of 0.755 than the value validated in original $\mathrm{MTBQ}(0.83)$ [9], indicating good reliability. The test-retest reliability coefficient of our questionnaire was 0.944 , which showed that the questionnaire had time consistency.
The MTBQ uses simple language and is suitable for elderly people to complete. The average time to complete the questionnaire was about 5 minutes, which was shorter than C-TBQ. The questionnaire has clear and detailed instructions. For investigators using the questionnaire, there are clear instructions on calculating, reporting and interpreting global MTBQ scores. However, there are also limitations. Firstly, the sample size was relatively small. Secondly, convenience sampling method were used and the samples were all from only one hospital in Zhengzhou, China, which may make it difficult to generalize the findings to a wider population in China. Moreover, this research only focused on older adults and the results may not be generalizable to younger people. Further research is needed to validate the C-MTBQ amongst younger people living in other provinces of China.

\section{Conclusion}

The Chinese version of multimorbidity treatment burden questionnaire (C-MTBQ) had good reliability and validity. It can be used as a patient-reported outcome measure to assess the treatment burden in Chinese-speaking elderly patients with multimorbidity in hospital.

Table 4 Correlation ( $r$ ) for the C-TBQ and C-TBQ subscales with the C-MTBQ of the Constant-Murley score

\begin{tabular}{|c|c|c|c|c|c|}
\hline Criterions & C-TBQ -medication & C-TBQ-seeing doctors and subsequent visit & C-TBQ-medical related and lifestyle & C-TBQ-health problem & TBQ \\
\hline C-MTBQ & 0.726 & 0.589 & 0.740 & 0.495 & 0.875 \\
\hline
\end{tabular}

C-MTBQ The Chinese version of the Multimorbidity Treatment Burden Questionnaire, C-TBQ The Chinese version of the Treatment Burden Questionnaire 


\section{Abbreviations}

MTBQ: Multimorbidity treatment burden questionnaire; TBQ: Treatment burden questionnaire; COSMIN: The Consensus-based Standards for the Selection of Health Measurement Instruments; ICC: Intra-class correlation coefficient; EFA: Exploratory factor analysis; C-MTBQ: The Chinese vesion of Multimorbidity treatment burden questionnaire; PCA: Principal-component analysis; SD: Standard deviation; CVI: Content validity index; S-CVI: Scale content validity index; I-CVI: Item content validity index; KMO: Kaiser-MeyerOlkin; PROM: Patient Reported Outcome Measures

\section{Acknowledgements}

The authors wish to thank all the study elderly participants with multimorbidity People's Hospital of Zhengzhou.

\section{Authors' contributions}

All authors participated in drafting or critically revising the article for important intellectual content. In addition, all authors approved the final version. $\mathrm{LD}$ and $\mathrm{JH}$ contributed equally to the work and should be considered as co-first authors. JH was the corresponding authors. Study concept and design were accomplished LD, JH and PD. Data acquisition was conducted by LD and LG. Data analysis and interpretation were completed by $L D$ and $J H$.

\section{Funding}

The study did not receive funding.

\section{Availability of data and materials}

Please contact author for data requests.

\section{Ethics approval and consent to participate}

All the participants signed informed consents, and this study was approved by the ethics committee of People's Hospital of Zhengzhou.

\section{Consent for publication}

Not applicable.

\section{Competing interests}

The authors declare that they have no competing of interests.

\section{Author details}

${ }^{1}$ School of Nursing and Health, Zhengzhou University, No.101, Kexue Road, Zhengzhou, Henan Province 450000, People's Republic of China. ${ }^{2}$ Party Secretary Office, People's Hospital of Zhengzhou, Zhengzhou, Henan Province 450000, People's Republic of China. ${ }^{3}$ Centre for Academic Primary Care, University of Bristol, Bristol BS6 6HL, UK.

Received: 10 December 2019 Accepted: 7 May 2020

Published online: 22 June 2020

\section{References}

1. Fortin M, Bravo G, Hudon C, et al. Prevalence of multimorbidity among adults seen in family practice. Ann Fam Med. 2005;3(3):223-8.

2. Kennedy BK, Berger SL, Brunet A, et al. Geroscience: linking aging to chronic disease. Cell. 2014;159(4):709-13.

3. Bähler C, Huber CA, Brüngger B, et al. Multimorbidity, health care utilization and costs in an elderly community-dwelling population: a claims data based observational study. BMC Health Serv Res. 2015;15(1):23.

4. Eton DT, Ramalho DOD, Egginton JS, et al. Building a measurement framework of burden of treatment in complex patients with chronic conditions: a qualitative study. Patient Relat Outcome Meas. 2012;3:39-49.

5. Zettl UK, Henze T, Essner U, et al. Burden of disease in multiple sclerosis patients with spasticity in Germany: mobility improvement study (move I). Eur J Health Econ. 2014;15(9):953-66.

6. Mair FS, May CR. Thinking about the burden of treatment. BMJ. 2014;349: g6680.

7. Kim S, Bennett K, Wallace E, et al. Measuring medication adherence in older community-dwelling patients with multimorbidity. Eur J Clin Pharmacol. 2018;74(3):357-64.

8. Kim S, Shin DW, Yun JM, et al. Medication adherence and the risk of cardiovascular mortality and hospitalization among patients with newly prescribed antihypertensive medications. Hypertension. 2016;67(3):506-12.
9. Duncan P, Murphy M, Man MS, et al. Development and validation of the multimorbidity treatment burden questionnaire (MTBQ). BMJ Open. 2018; 8(4):e19413.

10. Friisa $\mathrm{K}$, Lasgaarda $\mathrm{M}$, Pedersena $\mathrm{MH}$, et al. Health literacy, multimorbidity, and patient-perceived treatment burden in individuals with cardiovascular disease. A Danish population-based study. Patient Educ Couns. 2019;102(10): 1932-8.

11. Terwee CB, Bot SD, de Boer MR, et al. Quality criteria were proposed for measurement properties of health status questionnaires. J Clin Epidemiol. 2007;60(1):34-42.

12. Tran VT, Harrington M, Montori VM, et al. Adaptation and validation of the treatment burden questionnaire (TBQ) in English using an internet platform. BMC Med. 2014;12(1):1-9.

13. Ysrraelit MC, Fiol MP, Pena FV, et al. Adaptation and validation of a Spanish version of the treatment burden questionnaire in patients with multiple sclerosis. BMC Neurol. 2019;19(1):209.

14. Brislin RW. Back-translation for cross-cultural research[J]. J Cross Cult Psychol. 1970;1(3):185-216.

15. Acquadro C, CK H A. Quality of Life Assessment G. Literature review of methods to translate health-related quality of life questionnaires for use in multinational clinical trials. Value Health. 2008;11(3):509-21.

16. Guillemin FBCBD. Cross-cultural adaptation of healthrelated quality of life measures: literature review and proposed guidelines[J]. J Clin Epidemiol. 1993:46:1417-32.

17. Farin E, Heyduck K, Frye BC, et al. Translation and psychometric properties of the King's sarcoidosis questionnaire (KSQ) in German language. Health Qual Life Outcomes. 2019;17(1):62.

18. Floyd Fj WK. Factor analysis in the development and refinement of clinical assessment instruments. Psychol Assess. 1995;7(3):286.

19. Cappelleri JC, Bushmakin AG. Interpretation of patient-reported outcomes. Stat Methods Med Res. 2014;23(5):460-83.

20. Altman Dg SKMD, PC LTCG. The revised CONSORT statement for reporting randomized trials: explanation and elaboration. Ann Intern Med. 2001;134: 663-94.

21. Kruse JA, Williams RA, Mood D. Exploratory factor analysis of the strength of the cultural affiliation scale. Cancer Nurs. 2017;40(1):E28-35.

22. Naseri N, Baherimoghadam $T$, Rasooli $R$, et al. Validity and reliability of the Persian version of the psychosocial impact of dental aesthetics questionnaire. Health Qual Life Outcomes. 2019;17(1):126.

23. Kosari S, Deeks LS, Goss J, et al. Quality improvement of prescribing safety: a pilot study in primary care using UK electronic health records. Br J Gen Pract. 2019;69(687):490.

24. Wang J, Zuo H, Chen $X$, et al. Analysis of factors influencing the frequency of primary care visits among diabetic patients in two provinces in China. BMC Public Health. 2019;19(1):1267.

25. Chin WY, Wong C, Ng C, et al. Cultural adaptation and psychometric properties of the Chinese burden of treatment questionnaire (C-TBQ) in primary care patients with multi-morbidity. Fam Pract. 2019;36(5):657-65.

26. Chaplin K, Bower P, Man MS, et al. Understanding usual care for patients with multimorbidity: baseline data from a cluster-randomised trial of the 3D intervention in primary care. BMJ Open. 2018;8(8):e19845.

27. Yang ZP, Wang HX, Ou WS, et al. Current status of treatment burden of patients with noninfectious chronic diseases based on ordinal logistic regression. Chin General Practice. 2019;22(5):559-63.

\section{Publisher's Note}

Springer Nature remains neutral with regard to jurisdictional claims in published maps and institutional affiliations. 